\title{
Study of 1,2,4-triazole-3(5)-thiol Behavior in Reactions with 1-phenyl-1H-pyrrole-2,5-dione Derivatives and 3-bromodihydrofuran-2(3H)-one and Antimicrobial Activity of Products ${ }^{\dagger}$
}

\author{
Serhii Holota ${ }^{1,2, *}$, Halyna Derkach ${ }^{3}$, Olha Antoniv ${ }^{4}$, Natalia Slyvka ${ }^{2}$, Roman Kutsyk ${ }^{5}$, Andrzej Gzella ${ }^{6}$ \\ and Roman Lesyk ${ }^{1,7}$
}

Citation: Holota, S.; Derkach, H.; Antoniv, O.; Slyvka, N.; Kutsyk, R.; Gzella, A.; Lesyk, R. Study of 1,2,4triazole-3(5)-thiol Behavior in Reactions with 1-phenyl-1H-pyrrole2,5-dione Derivatives and 3-bromodihydrofuran-2(3H)-one and Antimicrobial Activity of Products. Chem. Proc. 2021, 3, 68. https://doi.org/10.3390/ecsoc-2408419

Academic Editors: Julio A. Seijas and M. Pilar Vázquez-Tato

Published: 14 November 2020

Publisher's Note: MDPI stays neutral with regard to jurisdictional claims in published maps and institutional affiliations.

Copyright: $\subset 2020$ by the authors. Licensee MDPI, Basel, Switzerland. This article is an open access article distributed under the terms and conditions of the Creative Commons Attribution (CC BY) license (http://creativecommons.org/licenses/by/4.0/).
1 Department of Pharmaceutical, Organic and Bioorganic Chemistry, Danylo Halytsky Lviv National Medical University, Pekarska 69, 79010 Lviv, Ukraine; roman.lesyk@gmail.com

2 Department of Organic Chemistry and Pharmacy, Lesya Ukrainka Volyn National University, Volya Avenue 13, 43025 Lutsk, Ukraine; natali.slyvka@ukr.net

3 Department of Chemistry of Pharmaceutical Faculty, Ivano-Frankivsk National Medical University, Halytska 2, 76018 Ivano-Frankivsk, Ukraine; derkachhalya@gmail.com

4 Department of Pharmacology, Danylo Halytsky Lviv National Medical University, Pekarska 69, 79010 Lviv, Ukraine; olga.antoniv@ukr.net

5 Department of Microbiology, Virology and Immunology, Ivano-Frankivsk National Medical University, Ivano-Frankivsk, Halytska 2, 76018 Ivano-Frankivsk, Ukraine; rkutsyk@ifnmu.edu.ua

6 Department of Organic Chemistry, Poznan University of Medical Sciences, Grunwaldzka 6, 60-780 Poznan, Poland; akgzella@ump.edu.pl

7 Department of Public Health, Dietetics and Lifestyle Disorders, Faculty of Medicine, University of Information Technology and Management in Rzeszow, Sucharskiego 2, 35-225 Rzeszow, Poland

* Correspondence: golota_serg@yahoo.com; Tel.: +380-972260066

+ Presented at the 24th International Electronic Conference on Synthetic Organic Chemistry, 15 November-15 December 2020; Available online: https://ecsoc-24.sciforum.net/.

\begin{abstract}
In present work we report our studies of the interaction of 1-phenyl- $1 H$-pyrrole-2,5-dione derivatives ( $N$-arylmaleimides) and 3-bromodihydrofuran-2 $(3 H)$-one ( $\alpha$-bromo- $\gamma$-butyrolactone) as possible $\left[\mathrm{C}_{2}\right]^{2+}$ synthons with 1,2,4-triazole-3(5)-thiole targeting on synthesis of novel 5-substituted thiazolo[3,2-b][1,2,4]triazole-6(5H)-ones. According to obtained results was establish that in above-mentioned interactions (conditions: convenient heating, range of solvents/reaction time) the thiol-ene click (for $N$-arylmaleimides) and $\mathrm{S}_{\mathrm{N}}$ (for $\alpha$-bromo- $\gamma$-butyrolactone) processes take place, but not [2+3]-cyclocondensation reaction. The structure of compounds was studied using ${ }^{1} \mathrm{H},{ }^{13} \mathrm{C}$ NMR spectroscopy, LC-MS spectrometry, and X-ray analysis. The prescreening of antimicrobial activity for synthesized compounds was performed against Gram-positive and Gram-negative bacteria, as well as yeasts.
\end{abstract}

Keywords: 1,2,4-triazole-3(5)-thiol; $N$-arylmaleimides; $\alpha$-bromo- $\gamma$-butyrolactone; thiol-ene click; $\mathrm{S}_{\mathrm{N}}$; [2+3]-cyclocondensation; antimicrobial/antifungal activity

\section{Introduction}

The thiazolo[3,2-b][1,2,4] triazole-6(5H)-one represent a bicyclic heteroatom-rich scaffold which recently, has considerably attracted the attention of medicinal chemists due to their diverse biological activities [1-3]. The [2+3]-cyclocondensation reaction of substituted 1,2,4-triazole-3(5)-thioles with equivalents of electrophilic synthon $\left[\mathrm{C}_{2}\right]^{2+}$ is key synthetic approach for 5-substituted thiazolo[3,2-b][1,2,4]triazole-6(5H)-ones [4]. The chloroacetic acid as $\left[\mathrm{C}_{2}\right]^{2+}$ synton is studied well (mostly in multicomponent reaction with aromatic/heteroaromatic aldehydes) [5-7] in interaction with substituted 1,2,4-triazole-3(5)- 
thioles meanwhile data about other ones are limited. Taking account that thiazole moiety in thiazolo[3,2-b][1,2,4] triazole-6(5H)-one core is structure equivalent of 4-thiazolidone ring and accordingly to retrosynthetic methodology it was logical to study the utilization of electrophilic synthon $\left[\mathrm{C}_{2}\right]^{2+}$ equivalents which normally used in 4-thiazolidone one synthesis. On the other hand, the 1,2,4-triazole-3(5)-thiol could be considered as a cyclic equivalent of thiosemicarbazide or formyl aldehyde thiosemicarbazone that allows expecting the formation of 4-thiazolidone core in the reaction process.

The wide range of 1,3-S,N-binucleophiles and electrophilic synthon $\left[\mathrm{C}_{2}\right]^{2+}$ equivalents are used in this type reaction provide to excellent structure diversity of target 4-thiazolidones. The recyclization of substituted 1-phenyl-1H-pyrrole-2,5-diones ( $N$-arylmaleimides) in interaction with $S, N$-binucleophiles is widely used as straightforward and convenient approach for synthesis of 2-(4-oxothiazolidin-5-yl)-N-R-phenylacetamides as well as respective annelated 4-thiazolidinone derivatives [8-12]. Some protocols describe utilization of 3-bromodihydrofuran-2(3H)-one ( $\alpha$-bromo- $\gamma$-butyrolactone) as $\left[\mathrm{C}_{2}\right]^{2+}$ syntons for synthesis of substituted 4-thiazolidinone derivatives in [2+3]-cyclocondensation reactions with row of $S, N$-binucleophiles. The thioamides [13], mono- and disubstituted thioureas [14], thiosemicarbazides and thiocarbohydrazides [15] react with $\alpha$-bromo- $\gamma$-butyrolactone by Hantzsch type reaction under mild conditions provides to appropriate 5-hydroxoethyl-4-thiazolidinone derivatives.

In our early study [5], we made an attempt to study the interaction of the 1,2,4-triazole-3(5)-thiol with $\mathrm{N}$-arylmaleimides (convenient heating, glacial acetic acid medium). We have described products of interaction of 1,2,4-triazole-3(5)-thiol with $N$-arylmaleimides as bicyclic functionalized derivatives of thiazolo[3,2-b][1,2,4]triazol-6(5H)-one [5]. Our conclusions have been made based on the spectral properties of compounds. The singlet signals in ${ }^{1} \mathrm{H}$ NMR spectra at $\delta=13.80-14.30$ ppm have played a key role in the structure determination of reaction products and have being interpreted as signals of NH- amide-group protons.

The similar structure determination of products is reported in later protocols $[16,17]$ describing the interaction of some substituted 1,2,4-triazole-3(5)-thiols and $N$-arylmaleimides. The conclusions about products structure in works $[16,17]$ were also performed based only on spectral data and obtaining of thiazolo[3,2-b][1,2,4]triazol-6(5H)-one system were argued using an interpretation of singlet signals in $1 \mathrm{H}$ NMR at $\delta=13.80-14.30 \mathrm{ppm}$ which were considered as signals of $\mathrm{NH}$ protons in amide group of appropriate 2-(6-oxo5,6-dihydrothiazolo[3,2-b][1,2,4]triazol-5-yl)- $N$-phenylacetamides. However, it should be noted that the similar singlet in a similar magnetic field can belong to signal of $\mathrm{NH}$ proton of 1,2,4-triazole ring. In work [18] we hypothesized and reported that interaction of some 1,2,4-triazole-3(5)-thiols with $N$-arylmaleimides does not lead to [2+3]-cyclocondensation products.

As a part of our ongoing interest to chemistry and pharmacology of azoles [19-22], in present paper we tried to study this issue more deeply using wide range of solvents/reaction conditions and clarify the structure of products in interactions of 1,2,4-triazole-3(5)thiol with $N$-arylmaleimides using $X$-ray technique. Moreover, we report about early undescribed interaction between $\alpha$-bromo- $\gamma$-butyrolactone and 1,2,4-triazole-3(5)-thiol and characterization of product. The paper also presents the screening results of antimicrobial activity for synthesized compounds against Gram-positive and Gram-negative bacteria, as well as yeasts. 


\section{Materials and Methods}

\subsection{General Experimental Methods}

Melting points were measured in open capillary tubes on a BÜCHI B-545 melting point apparatus (BÜCHI Labortechnik AG, Flawil, Switzerland) and are uncorrected. The elemental analyses $(\mathrm{C}, \mathrm{H}, \mathrm{N})$ were performed using the Perkin-Elmer $2400 \mathrm{CHN}$ analyzer (PerkinElmer, Waltham, MA, USA) and were within $\pm 0.4 \%$ of the theoretical values. The $500 \mathrm{MHz}^{-1} \mathrm{H}$ and $126 \mathrm{MHz}^{-13} \mathrm{C}$ spectra were recorded on Bruker AVANCE-500 spectrometer (Bruker, Bremen, Germany). All spectra were recorded at room temperature except where indicated otherwise and were referenced internally to solvent reference frequencies. Chemical shifts $(\delta)$ are quoted in ppm and coupling constants $(\mathrm{J})$ are reported in $\mathrm{Hz}$. LC-MS spectra were obtained on a Finnigan MAT INCOS-50 (Thermo Finnigan LLC, San Jose, CA, USA). Solvents and reagents that are commercially available were used without further purification. The synthesis of compound 1 was performed as described in [23], the synthesis and spectral properties of compound $\mathbf{2} \mathbf{a}-\mathbf{f}$ were early described in [5].

\subsection{The Synthesis of 3-((1H-1,2,4-triazol-3-yl)thio)dihydrofuran-2(3H)-one (3)}

A mixture of $1 H$-1,2,4-triazole-5-thiol (1) (10.0 mmol), 3-bromodihydrofuran-2(3H)one ( $\alpha$-bromo- $\gamma$-butyrolactone) $(10.0 \mathrm{mmol})$ and anhydrous sodium acetate $(10.0 \mathrm{mmol}$, medium- $10 \mathrm{~mL}$ of glacial acetic acid) or triethylamine $(10.0 \mathrm{mmol}$, medium- $10 \mathrm{~mL}$ of ethanol) refluxed for $30 \mathrm{~min}$ to $24 \mathrm{~h}$. After cooling to the room temperature and evaporated the resulting masse were treated with diethyl ether and recrystallized from mixture acetonitrile-water.

Beige prismes, yield $45 \%, \mathrm{mp} 67-70{ }^{\circ} \mathrm{C} .{ }^{1} \mathrm{H}$ NMR $(500 \mathrm{MHz}$, DMSO-d6, $\delta$ ): 14.20 (br.s, $1 \mathrm{H}, \mathrm{NH}, 1,2,4$-triazole), $8.53(\mathrm{~s}, 1 \mathrm{H}, 1,2,4$-triazole), $4.53(\mathrm{t}, J=9.4 \mathrm{~Hz}, 1 \mathrm{H}, \mathrm{CH}), 4.36(\mathrm{td}, J=$ $\left.8.8,3.2 \mathrm{~Hz}, 1 \mathrm{H}, \mathrm{CH}_{2}\right), 4.28\left(\mathrm{td}, J=8.8,7.1 \mathrm{~Hz}, \mathrm{CH}_{2}\right), 2.71(\mathrm{dddd}, J=12.5,9.2,7.1,3.2 \mathrm{~Hz}, 1 \mathrm{H}$, $\left.\mathrm{CH}_{2}\right), 2.43\left(\mathrm{dq}, J=12.6,9.0 \mathrm{~Hz}, 1 \mathrm{H}, \mathrm{CH}_{2}\right) .{ }^{13} \mathrm{C}$ NMR $(126 \mathrm{MHz}, \mathrm{DMSO}-\mathrm{d} 6, \delta): 174.82(\mathrm{C}=\mathrm{O})$, 155.96 (1,2,4-triazol), 146.10 (1,2,4-triazol), $66.80\left(\mathrm{CH}_{2}-\mathrm{O}\right), 42.20(\mathrm{CH}), 29.27\left(\mathrm{CH}_{2}\right)$. LCMS (ESI+) m/z $186(\mathrm{M}+\mathrm{H})^{+}$. Calc. for $\mathrm{C}_{6} \mathrm{H}_{7} \mathrm{~N}_{3} \mathrm{O}_{2} \mathrm{~S}$ : C $38.91 \%$, H 3.81\%, N 22.69\%. Found: C $39.00 \%$, H $3.90 \%$, N $22.90 \%$.

\subsection{Antimicrobial Activity}

The antimicrobial activity of the compounds $\mathbf{2 a}, \mathbf{2} \mathbf{d}$, and $\mathbf{2 e}$ was determined by the agar diffusion method [24,25]. Nutrient agar $(0.5 \%$ peptone, $0.3 \%$ beef extract, $1.5 \%$ agar, $0.5 \%$ sodium chloride, distilled water, $\mathrm{pH} \sim 6.8$ ) was used as a nutrient medium. The test cultures suspensions (in concentration $1 \times 10^{7} \mathrm{CFU} / \mathrm{mL}$ ), standardized previously by the optical standard of turbidity, were uniformly sown in Petri dishes with the nutrient agar. Aliquots $(20 \mu \mathrm{L})$ of $0.1 \%$ tested derivatives (concentration $1000 \mu \mathrm{g} / \mathrm{mL}$ ) in $\mathrm{EtOH} / \mathrm{DMSO} /$ water (2:1:1) were placed into wells (diameter of $4.0 \pm 0.1 \mathrm{~mm}$ ) in agar in Petri plates with test microorganisms. The antimicrobial activity was evaluated by measuring the diameter of zone inhibition of microbial growth. The plates were incubated for $24 \mathrm{~h}$ at $37^{\circ} \mathrm{C}$. The inhibition zone appeared after $24 \mathrm{~h}$ and was measured in $\mathrm{mm}$ around the well in each plate. Digital images of culture growth on dishes were obtained and processed with a computer program UTHSCSA ImageTool 2.0 (The University of Texas Health Science Center in San Antonio, San Antonio, TX, USA, (C 1995-1996) for calculation of growth inhibition zone diameters. Each experiment was performed in triplicate. Results were expressed as the means \pm S.D. The experiments were carried out on microorganism strains, which were isolated in the laboratory of the microbiology research of the Department of Microbiology, Virology and Immunology of the Ivano-Frankivsk National Medical University from ambulatory patients. The following bacterial strains were used: methicillin-sensitive Staphylococcus aureus ATCC 25,923 (MSSA); methicillin-resistant Staphylococcus aureus (MRSA), clinical isolate; methicillin-resistant Staphylococcus epidermidis (MRSE), clinical isolate; Escherichia coli ATCC 25922; yeasts Candida albicans (clinical isolate). Staphylococci of clinic origin were identified using chemical micro-tests 
"STAPHYtest 16" (Lachema, Czech Republic). Fungi culture was identified on the basis of 40 biochemical tests using the VITEK 2 system with the VITEK 2 YST ID card (bioMerieux, Craponne, France). The sensitivity of strains to antibiotics was determined by disc diffusion and serial dilutions methods.

\section{Results and Discussion}

\subsection{Chemical Synthesis and Structure Determination}

According to our objectives, we revised our previous protocol and studied interaction of 1,2,4-triazole-3(5)-thiol (1.0 eq) with series of $N$-arylmaleimides (1.0 eq) using convenient heating and wide range of solvents: polar protic (acetic acid, ethanol), polar aprotic (acetone, acetonitrile), and non-polar (benzene, toluene) (Scheme 1). The reflux of reaction mixtures was performed in time range from $30 \mathrm{~min}$ to $24 \mathrm{~h}$ and was monitored by TLC. The spots of starting reagents and only of one new product in each reaction were observed in TLC within all the time. The increase of reaction time duration does not lead to a significant yield increase even after $24 \mathrm{~h}$ reflux as wells as to formation of new products. The addition of the anhydrous $\mathrm{AcONa}$ in the reaction mixture did not lead to obtaining new products too.

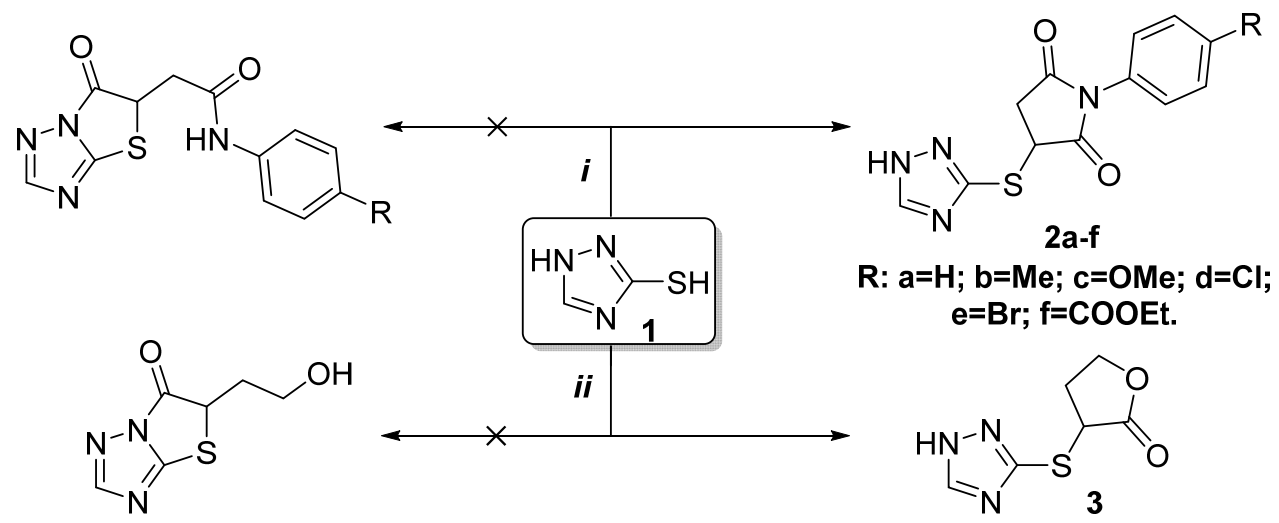

Scheme 1. Synthesis of non-condensed 3-(1H-[1,2,4]triazol-3-ylsulfanyl)-derivatives 2a-f, 3. Reagents and conditions: (i) 1,2,4-triazole-3(5)-thiol (1) (1.0 eq.); N-arylmaleimides (1.0 eq.); studied solvents: acetic acid, ethanol, acetone, acetonitrile, benzene, toluene; without or in presence of AcONa anhydrous (1.0 eq.); reflux from $30 \mathrm{~min}$ to $24 \mathrm{~h}$; (ii) 1,2,4-triazole-3(5)-thiol (1) (1.0 eq.); $\alpha$ bromo- $\gamma$-butyrolactone (1.0 eq.); studied solvents: acetic acid, ethanol; in presence of AcONa anhydrous (1.0 eq.) or triethylamine (1.0 eq.); reflux from $30 \mathrm{~min}$ to $24 \mathrm{~h}$.

Since the application of spectral methods to analyze the structure of products is not completely convincing the X-ray crystallographic analysis was used for structure determination of compounds $\mathbf{2} \mathbf{b}$ and $\mathbf{2 e}$. The ORTEP drawing and atomic numbering are shown in Figure 1.

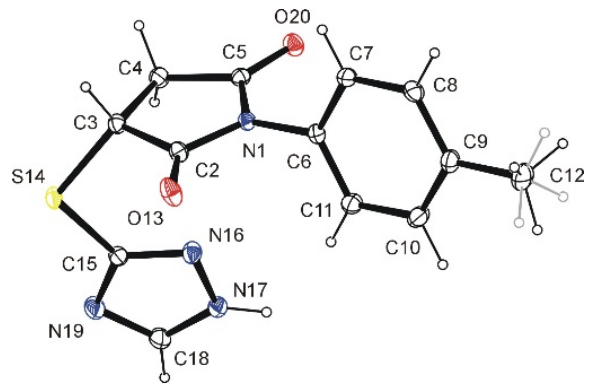

$2 b$

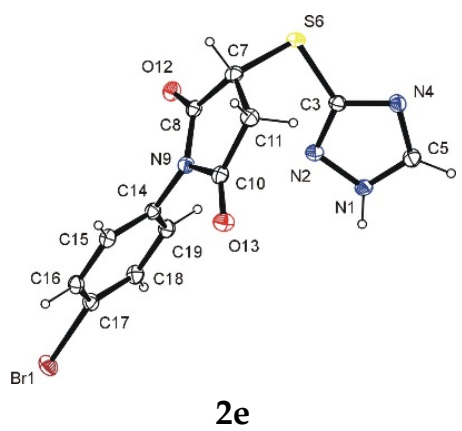

$2 e$

Figure 1. The molecular structures of $\mathbf{2 b}$ and $\mathbf{2 e}$. 
The reaction between 1,2,4-triazole-3(5)-thiol (1.0 eq.) and $\alpha$-bromo- $\gamma$-butyrolactone (1.0 eq.) were studied in glacial acetic acid and ethanol medium. Such bases as anhydrous sodium acetate (1.0 eq.) and triethylamine (1.0 eq.) were used for reaction. The process was monitored by TLC. It should be noted that nucleophilic substitution is very fast process in mentioned conditions and $\mathrm{S}_{\mathrm{N}}$ product's (compound 3, Scheme 1) spot had been observed in TLC already after 10-15 min of reflux. The extending of reflux even to $24 \mathrm{~h}$ did not lead to the formation of new products accordingly to TLC and finally LC-MS, NMR data. In the ${ }^{1} \mathrm{H}$ NMR spectrum of compound 3 the broad signal at $14.20 \mathrm{ppm}$ belongs to the $\mathrm{NH}$ proton of 1,2,4-triazole ring and indicates the absence of bicyclic annelated product (Figure 2).

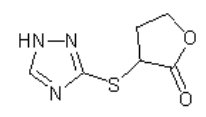

3

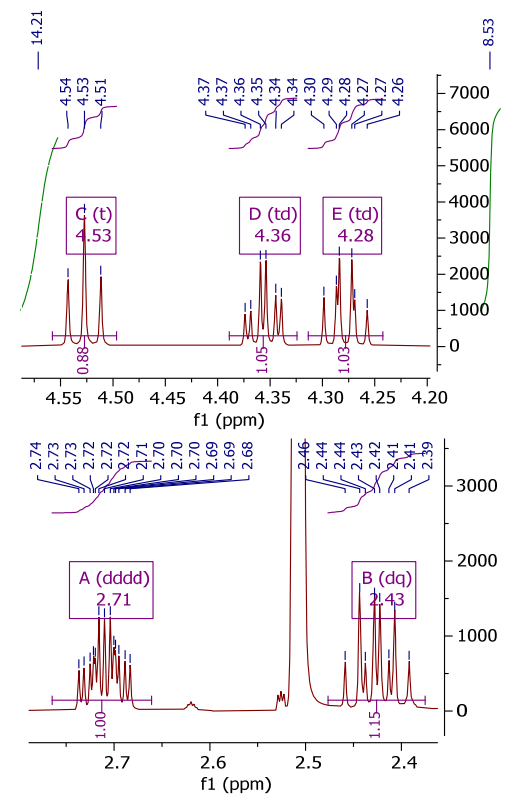

$\underset{\substack{n \\ \infty}}{\infty}$

000

5000

000

000

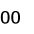
$\mid$ $-7000$

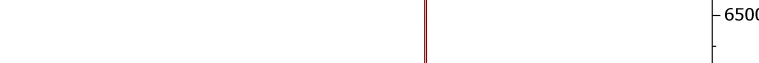

$-5500$

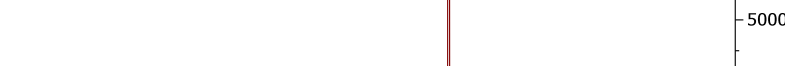

$-4500$

$-4000$

3500

$-3000$

$-2500$

2000

$-1500$

1000

$-500$

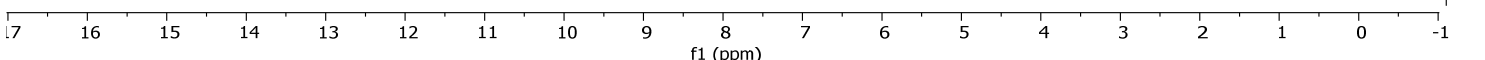

Figure 2. ${ }^{1} \mathrm{H}$ NMR spectrum of compound 3.

The signals of protons of furan-2(3H)-one moiety give a characteristic pattern for cyclic lactone ring [26] with triplet at $4.53(J=9.4 \mathrm{~Hz})$; triplets of doublets at $4.36(J=8.8,3.2$ $\mathrm{Hz})$, and $4.28(J=8.8,7.1 \mathrm{~Hz})$; doublet of doublet of doublet of doublets at $2.71(\mathrm{~J}=12.5$, 9.2, 7.1, 3.2 Hz), and doublet of quartet at $2.43(J=12.6,9.0 \mathrm{~Hz}$ ) (Figure 2).

\subsection{Antimicrobial Activity}

The compounds $\mathbf{2} \mathbf{a}, \mathbf{2} \mathbf{d}$, and $\mathbf{2} \mathbf{e}$ were pre-screened for their potential antimicrobial activities against Gram-positive bacterium (Staphylococcus aureus, S. aureus; Staphylococcus epidermidis, S. epidermidis), Gram-negative bacterium (Escherichia coli, E. coli) and yeasts (Candida albicans, C. albicans). The antimicrobial activity was evaluated in terms of zone of growth inhibition and values were compared to standard reference antimicrobial agents $[24,25]$. The tested compounds were found highly active against methicillin-resistant strains oS. aureus (MRSA) and S. epidermidis (MRSE), as well as C. albicans (Table 1). 
Table 1. In vitro antimicrobial activity of compounds 2a, 2d, and 2e. Zone of growth inhibition (in $\mathrm{mm}$, at conc. $200 \mu \mathrm{g} / \mathrm{mL}$ after $24 \mathrm{~h}, \mathrm{M} \pm \mathrm{S}(\sigma))$.

\begin{tabular}{cccccc}
\hline \multirow{2}{*}{$\begin{array}{c}\text { Compound, } \\
\text { Refeerence Drugs }\end{array}$} & \begin{tabular}{c} 
S. aureus \\
\cline { 2 - 6 } ATCC 25,923 MSSA
\end{tabular} & $\begin{array}{c}\text { S. aureus } \\
\text { MRSA }^{\text {a }}\end{array}$ & $\begin{array}{c}\text { S.epidermidis } \\
\text { MRSE }^{\text {a }}\end{array}$ & $\begin{array}{c}\text { E. coli } \\
\text { ATCC 25922 }\end{array}$ & ${\text { C. } \text { albicans }^{\text {a }}}^{\text {2a }}$ \\
2a & $7.40 \pm 0.40$ & $8.55 \pm 0.24$ & $8.55 \pm 0.24$ & - & $11.03 \pm 0.61$ \\
2d & $9.13 \pm 0.43$ & $7.89 \pm 0.30$ & $9.83 \pm 0.20$ & - & $12.58 \pm 0.75$ \\
2e & $14.06 \pm 0.51$ & $17.25 \pm 0.38$ & $15.50 \pm 0.50$ & $8.00 \pm 0.48$ & $12.75 \pm 0.45$ \\
Ampicillin, $10.0 \mu \mathrm{g} / \mathrm{mL}$ & $23.58 \pm 0.63$ & $7.69 \pm 0.28$ & $7.88 \pm 0.34$ & $16.80 \pm 0.40$ & - \\
Fluconazole, $10.0 \mu \mathrm{g} / \mathrm{mL}$ & - & - & - & - & $14.71 \pm 0.39$ \\
\hline
\end{tabular}

a-clinical isolate; "_"-compounds not tested in experiment.

The antibacterial screening results indicated that nature of substituent in synthesized derivatives of 1-(phenyl)-3-(2H-[1,2,4]triazol-3-ylsulfanyl)-pyrrolidine-2,5-dione has impact on activity level and antibacterial/antifungal properties increase as follows: 4- $\mathrm{H}>4$ $\mathrm{Cl}>4 \mathrm{Br}$.

\section{Conclusions}

In present report the interaction of 1,2,4-triazole-3(5)-thiol with such electrophilic synthons $\left[\mathrm{C}_{2}\right]^{2+}$ equivalents as $N$-arylmaleimides and $\alpha$-bromo- $\gamma$-butyrolactone have been studied. The X-ray analysis and spectral methods were used for products structure determination. According to dates was establish that in mentioned interactions the thiol-ene click process and nucleophilic substitution take place, but not [2+3]-cyclocondensation reaction as could be expected. The obtained results of pharmacological screening suggest to coming design and synthesis of new 1,2,4-triazol/pyrrolidine-2,5-dione hybrids as potential molecules with promising antimicrobial properties.

Author Contributions: Conceptualization, S.H. and R.L.; methodology, S.H. and R.L; synthesis of compounds, S.H. and R.L.; pharmacological screening, H.D., O.A., and R.K.; spectral study, S.H. and N.S.; X-ray study, A.G. writing-original draft preparation, S.H.; writing-review and editing, S.H., R.K., A.G., and R.L. All authors have read and agreed to the published version of the manuscript.

Funding: This work was partially supported by COST Action NutRedOx-CA16112 "Personalized Nutrition in aging society: redox control of major age-related diseases" (for S.H.).

Acknowledgments: This research was supported by the Danylo Halytsky Lviv National Medical University, which is gratefully acknowledged.

Conflicts of Interest: The authors declare no conflict of interest.

\section{References}

1. Sheng, C.; Miao, Z.; Zhang, W. New strategies in the discovery of novel non-camptothecin topoisomerase I inhibitors. Curr. Med. Chem. 2011, 18, 4389-4409, doi:10.2174/092986711797200453.

2. Assarzadeh, M.J.; Almasirad, A.; Shafiee, A.; Koopaei, M.N.; Abdollahi, M. Synthesis of new thiazolo[3,2-b][1,2,4]triazole-6(5H)one derivatives as potent analgesic and anti-inflammatory agents. Med. Chem. Res. 2014, 23, 948-957, doi:10.1007/s00044-0130697-y.

3. Toma, A.; Mogoşan, C.; Vlase, L.; Leonte, D.; Zaharia, V. Heterocycles 39. Synthesis, characterization and evaluation of the antiinflammatory activity of thiazolo[3,2-b][1,2,4]triazole derivatives bearing pyridin-3/4-yl moiety. Med. Chem. Res. 2017, 26, 26022613, doi:10.1007/s00044-017-1959-x.

4. Slivka, M.V.; Korol, N.I.; Fizer, M.M. Fused bicyclic 1,2,4-triazoles with one extra sulfur atom: Synthesis, properties, and biological activity. J. Heterocycl. Chem. 2020, 57, 3236-3254, doi:10.1002/jhet.4044.

5. Lesyk, R.; Vladzimirska, O.; Holota, S.; Zaprutko, L.; Gzella, A. New 5-substituted thiazolo[3,2-b][1,2,4]triazol-6-ones: Synthesis and anticancer evaluation. Eur. J. Med. Chem. 2007, 42, 641-648, doi:10.1016/j.ejmech.2006.12.006.

6. Uzgören-Baran, A.; Tel, B.C.; Sarıgöl, D.; Oztürk, E.İ.; Kazkayası, I.; Okay, G.; Ertan, M.; Tozkoparan, B. Thiazolo[3,2-b]-1,2,4triazole-5(6H)-one substituted with ibuprofen: Novel non-steroidal anti-inflammatory agents with favorable gastrointestinal tolerance. Eur. J. Med. Chem. 2012, 57, 398-406, doi:10.1016/j.ejmech.2012.07.009. PMID: 22840494. 
7. Holota, S.; Shylych, Y.; Derkach, H.; Karpenko, O.; Gzella, A.; Lesyk, R. Synthesis of 4-(2H-[1,2,4]-Triazol-5-ylsulfanyl)-1,2-dihydropyrazol-3-one via Ring-Switching Hydrazinolysis of 5-Ethoxymethylidenethiazolo[3,2-b][1,2,4]triazol-6-one. Molbank 2018, 2018, M1022, doi:10.3390/M1022.

8. Shimo, T.; Matsuda, Y.; Iwanaga, T.; Shinmyozu, T.; Somekawa, K. Efficient 2-Amino-2-thiazolin-4-ones or 2-Iminothiazolidin4-ones Formation from Thioureas and Maleimides under Solvent-Free Conditions. Heterocycles 2007, 71, $1053-1058$.

9. Pankova, A.S.; Golubev, P.R.; Khlebnikov, A.F.; Ivanov, A.Y.; Kuznetsov, M.A. Thiazol-4-one derivatives from the reaction of monosubstituted thioureas with maleimides: Structures and factors determining the selectivity and tautomeric equilibrium in solution. Beilstein. J. Org. Chem. 2016, 12, 2563-2569, doi:10.3762/bjoc.12.251.

10. Achoui, N.; Zaioua, K.; Hammoutène, D.; Kolli-Nedjar, B.; Akacem, Y. Interaction of thiourea and urea with maleimide: Comparative theoretical DFT study. Heliyon 2019, 5, e02330, doi:10.1016/j.heliyon.2019.e02330.

11. Troin, Y.; Bentarzi, Y.; Nedjar-Kolli, Y.; Plas, A.; Chalard, P. Synthesis of 2-thioxoimidazolin-4-one and thiazolo[3,2-a]-benzimidazole derivatives from substituted maleimides Arkivoc 2010, 10, 328-337.

12. Hahn, H.G.; Nam, K.; Mah, H. A simple construction of 2-phenylimino-1,3-thiazolidin-4-ones. Heterocycles 2001, 55, 1283-1289.

13. Sogame, S.; Suenaga, Y.; Atobe, M.; Kawanishi, M.; Tanaka, E.; Miyoshi, S. Discovery of a benzimidazole series of ADAMTS-5 (aggrecanase-2) inhibitors by scaffold hopping. Eur. J. Med. Chem. 2014, 71, 250-258, doi:10.1016/j.ejmech.2013.10.075.

14. Vanaa, J.; Hanusek, J.; Ruzicka, A.; Sedlaka, M. Efficient Synthesis of 5-(2-Hydroxyethyl)-2-phenylimino-1,3-thiazolidin-4-ones and 5-(2-Hydroxyethyl)-2-phenylamino-4,5-dihydro-1,3-thiazol-4-ones. J. Heterocycl. Chem. 2009, 46, 635-639, doi:10.1002/jhet.

15. Kabashima, S.H.; Okawara, T.; Yamasaki, T.; Furukawa, M. Synthesis of Novel 1,3-Thiazolidines and 1,3,4-Thiadiazolines from Thiocarbohydrazines. Heterocycles 1990, 31, 1129-1139, doi:10.3987/COM-90-5380.

16. Kumsi, M.; Poojary, B.; Lobo, P.L.; Fernandes, J.; Chikkanna, C. Synthesis of Some Fused Triazole Derivatives Containing 4Isobutylphenylethyl and 4-Methylthiophenyl Moieties. Z. Naturforsch. B 2010, 65, 1353-1358, doi:10.1515/znb-2010-1110.

17. Lobo, P.; Poojary, B.; Manjunatha, K.; Kumari, N.S. Synthesis and Antimicrobial Evaluation of Some New 2-(6-Oxo-5,6- dihydro[1,3]thiazolo[3,2-b]-2-aryloxymethyl-1,2,4-triazol-5-yl)-arylacetamides. Z. Naturforsch. B 2014, 65, 617-624, doi:10.1515/znb2010-0512.

18. Pyrih, A.; Berninger, M.; Gzella, A.; Lesyk, R.; Holzgrabe, U. Synthesis and evaluation of antitrypanosomal activity of some thiosemicarbazide derivatives of 1-butyl-6-fluoro-7-morpholino-4-oxo-1, 4-dihydroquinoline-3-carboxylic acid. Synth. Comm. 2018, 48, 1883-1891.

19. Golota, S.; Sydorenko, I.; Surma, R.; Karpenko, O.; Gzella, A.; Lesyk, R. Facile one-pot synthesis of 5-aryl/heterylidene-2-(2hydroxyethyl- and 3-hydroxypropylamino)-thiazol-4-ones via catalytic aminolysis. Synth. Comm. 2017, 47, $1071-1076$.

20. Holota, S.M.; Derkach, H.O.; Demchuk, I.L.; Vynnytska, R.B.; Antoniv, O.I.; Furdychko, L.O.; Slyvka, N.Y.; Nektegayev, I.O.; Lesyk, R.B. Synthesis and in vivo evaluation of pyrazoline-thiazolidin-4-one hybrid Les-5581 as a potential non-steroidal antiinflammatory agent. Biopolym. Cell 2019, 35, 437-447, doi:10.7124/bc.000A17.

21. Holota, S.M.; Derkach, G.O.; Zasidko, V.V.; Trokhymchuk, V.V.; Furdychko, L.O.; Demchuk, I.L.; Semenciv, G.M.; Soronovych, I.I.; Kutsyk, R.V.; Lesyk, R.B. Features of antimicrobial activity of some 5-aminomethylene-2-thioxo-4-thiazolidinones. Biopolym. Cell 2019, 35, 371-380, doi:10.7124/bc.000A0E.

22. Schadich, E.; Kryshchyshyn-Dylevych, A.; Holota, S.; Polishchuk, P.; Džubak, P.; Gurska, S.; Hajduch, M.; Lesyk, R. Assessing different thiazolidine and thiazole based compounds as antileishmanial scaffolds. Bioorg. Med. Chem. Lett. 2020, 30, 127616, doi:10.1016/j.bmcl.2020.127616. PMID: 33091607.

23. Ainsworth, C. 1,2,4-Triazole. Org. Synth. 1960, 40, 99, doi:10.15227/orgsyn.040.0099.

24. Humphries, R.M.; Ambler, J.; Mitchell, S.L.; Castanheira, M.; Dingle, T.; Hindler, J.A.; Koeth, L.; Sei, K. CLSI Methods Development and Standardization Working Group of the Subcommittee on Antimicrobial Susceptibility Testing. CLSI Methods Development and Standardization Working Group Best Practices for Evaluation of Antimicrobial Susceptibility Tests. J. Clin. Microbiol. 2018, 56, e1917-e1934, doi:10.1128/JCM.01934-17. PMID: 29367292.

25. Nenoff, P.; Oswald, U.; Haustein, U.F. In vitro susceptibility of yeasts for fluconazole and itraconazole. Evaluation of a microdilution test. Mycoses 1999, 42, 629-639, doi:10.1046/j.1439-0507.1999.00510.x. PMID: 10680439.

26. Filippi, J.-J.; Fernandez, X.; Lizzani-Cuvelier, L.; Loiseau, A.-M. Syntheses and olfactory characteristics of flavouring and perfuming lactone thiono-analogues. Flav. Fragr. J. 2005, 21, 175-184, doi:10.1002/ffj.1559. 